\title{
Timely and/or Controversial Information for Family Physicians
}

\author{
Marjorie A. Bowman, MD, MPA, Anne Victoria Neale, PhD, MPH, \\ and Dean A. Seebusen, MD, MPH
}

Plan to spend some time reading this information-dense issue with a large amount of new material and ideas. From the humanoid behavioral health coach to tackling the controversial topic of environmental causes of autism spectrum disorders, this issue encompasses a broad range of topics. New anticoagulants for an extremely common entity, atrial fibrillation, are discussed. Learn about the shocking increase in oropharyngeal cancers with a changing epidemiology: younger patients with a different clinical presentations. Researchers evaluate changes after new or revised guidelines. "Near miss" reporting can facilitate quality improvement. Pets can make humans ill, yet they are beloved and can improve the health of their human owners. (J Am Board Fam Med 2015;28:435-437.)

Artificial intelligence is here in the form of a responsive, online, talking electronic humanoid that successfully provides behavior change counseling. Congratulations to Jack et $\mathrm{al}^{1}$ for this early report on a new "conversational agent" that might work, both electronically and in terms of effect on patient behavior. Interestingly, they called the humanoid "Gabby," which in informal terminology means "talkative." We look forward to much more in this clinical territory. This seems so magical, and so increases our hopes for the positive aspects of computers. Please, can someone find an easy electronic solution to creating terrific medical records without ever having to type, dictate, or click boxes; we do not care how humanoid this magical solution will seem-a humanoid scribe is fine.

Crane et $\mathrm{al}^{2}$ report the use of "near-miss" reporting as a quality improvement tool in primary care. Compared with reporting of adverse events, reporting of near misses can help identify problems in a practice before a negative outcome occurs. The reporting of near misses is more common in hospitals than ambulatory practices, but this article certainly provides reason for more practices to start using this quality improvement tool.

The causes of attention-deficit hyperactive disorder and autism are unknown, highly debated, and

Conflict of interest: The authors are editors for the $7 A B F M$. of strong interest; they are chronic diseases with many negative implications for affected individuals, their families, and our society. Heilbrun et $\mathrm{al}^{3}$ present a fascinating exploratory survey of maternal chemical intolerances and the likelihood of reporting a child with either autism or attention-deficit hyperactive disorder. The potential mechanism for a relationship to either disorder is not clear. Heilbrun et al recognize potential problems with their method: Study participants were recruited from topic-oriented websites and recruited their own controls, and both participants and controls were highly educated. We hope to see further studies with broader patient populations and stronger methodologies follow up on the hypotheses suggested in this article.

The impact of the Choosing Wisely campaign is unknown, yet the campaign is fairly widely known and sometimes debated. Kost et $\mathrm{al}^{4}$ reviewed what happened in their practice before and after the campaign, while adding a 1-hour intervention. Their office should be reassured that there was already a high level of agreement between the campaign recommendations and their practices. But improvement was still possible, even with such a high level of initial adherence to the recommended guidelines.

In a similar type of report, $\mathrm{Li}$ et $\mathrm{al},{ }^{5}$ from the Centers for Disease Control and Prevention, looked at changes in the amount of prostate cancer 
testing after changes in the recommendations of the US Preventive Services Task Force in 2008 and 2012. In contrast to the article by Kost et al, ${ }^{4} \mathrm{Li}$ et al identified much testing that was not in accordance with the guidelines, both before and after the guidelines were published. Although concordance increased, men $\geq 75$ years old still received the most prostate-specific antigen testing. Obviously it is tough to get absolute agreement on this topic because so many patients and physicians have come to believe that prostate-specific antigen testing can thwart an early death.

In other cancer news, human papillomavirus (HPV)-positive (HPV+) and HPV-negative oropharyngeal carcinomas are significantly different, and the number and proportion of $\mathrm{HPV}+$ cancers is growing quickly. ${ }^{6}$ Patients with HPV+ oropharyngeal carcinomas are likely to present to primary care clinicians, not emergency rooms or ear, nose, and throat specialist physicians. HPV + patients diagnosed in primary care have a different profile, and their prognosis is different. Readers, time to get updated on the latest knowledge in this article.

We find reassuring news from Schlichting et $\mathrm{al}^{7}$ that many veterans who tested once will continue to participate in fecal occult blood tests for colorectal cancer screening after the first round of testing. In fact, they preferred this annual testing to colonoscopy every 10 years. Regarding melanoma cancers, Snyder and colleagues ${ }^{8}$ provide information on techniques to obtain an adequate specimen for diagnosis.

Reflecting the broad scope of primary care, this month we have other clinical reviews and updates on current clinical information and topics. Hodgson et $\mathrm{al}^{9}$ present many aspects of the positive ("zooeyia") and negative health effects of pet ownership. We know how much many people love their pets, treating them as family, and that pet ownership can provide positive health effects. People also occasionally die in an attempt to save their pets. Pet deaths can also provoke major grief reactions.

Home sleep tests for obstructive sleep apnea, but not for other types of sleep disorders, are available and can be quite useful in some circumstances. Kapoor and Greenough ${ }^{10}$ provide information on differences between in-laboratory polysomnography and home testing that affect test interpretation and follow-up. Most home sleep test versions do not include electroencephalography, and none can currently provide continuous positive airway pressure titration.

The article by Mookadam et $\mathrm{al}^{11}$ on the place of novel oral anticoagulants is welcome in light of the high rate of atrial fibrillation in practice, the sheer number of new medicines, the substantially different pros and cons of their use-in turn effecting who should be treated with what drug - and how to respond to likely clinical circumstances such as planned or unplanned surgeries. Read this article to help sort out treatment options.

Body mass index is little understood by patients. ${ }^{12}$ Would increasing their understanding increase the effort to improve personal body mass index values? In another report, Davis et $\mathrm{al}^{13}$ indicate that chiropractors seem to displace some visits for back and neck pain that would otherwise be seen by primary care physicians.

Our shorter pieces include one in which a family physician explores his personal, emotional transition from a doctor delivering babies to one who "births" in a different way. ${ }^{14}$ The American Board of Family Medicine reports that a substantial group of the initial physician cohort that took their first examination in 1970 to 1971 (and are now aged 70 to 94 years) continue to recertify. ${ }^{15}$ In general, this means they have recertified 6 or 7 times. It is reassuring that older family physicians continue to be interested in keeping their knowledge base up to date.

\section{References}

1. Jack B, Bickmore T, Hempstead M, et al. Reducing preconception risks among African American women with conversational agent technology. J Am Board Fam Med 2015;28:441-51.

2. Crane S, Sloane PD, Elder N, et al. Reporting and using near-miss events to improve patient safety in diverse primary care practices: a collaborative approach to learning from our mistakes. J Am Board Fam Med 2015;28:452-60.

3. Heilbrun LP, Palmer RF, Jaen CR, Svoboda MD, Miller CS, Perkins J. Maternal chemical and drug intolerances: potential risk factors for autism and attention deficit hyperactivity disorder (ADHD). J Am Board Fam Med 2015;28:461-70.

4. Kost A, Genao I, Lee JW, Smith SR. Clinical decisions made in primary care clinics before and after Choosing Wisely ${ }^{\mathrm{TM}}$. J Am Board Fam Med 2015;28:471-4.

5. Li J, Berkowitz Z, Hall IJ. Decrease in prostate cancer testing following the US Preventive Services Task Force (USPSTF) recommendations. J Am Board Fam Med 2015;28:491-3.

6. Moore KA II, Mehta V. The growing epidemic of 
HPV-positive oropharyngeal carcinoma: a clinical review for primary care providers. J Am Board Fam Med 2015;28:498-503.

7. Schlichting JA, Mengeling MA, Makki NM, et al. Veterans' continued participation in an annual fecal immunochemical test mailing program for colorectal cancer screening. J Am Board Fam Med 2015;28: 494-7.

8. Snyder A, West SE, Miles CM, Feldman SR. Obtaining an adequate specimen for the diagnosis of pigmented lesions. J Am Board Fam Med 2015;28: 523-5.

9. Hodgson K, Barton L, Darling M, Antao V, Kim FA, Monavvari A. Pets' impact on your patients' health: leveraging benefits and mitigating risk. J Am Board Fam Med 2015;28:526-34.

10. Kapoor M, Greenough G. Home sleep tests for obstructive sleep apnea (OSA). J Am Board Fam Med 2015;28:504-9.
11. Mookadam M, Shamoun FE, Mookadam F. Novel anticoagulants in atrial fibrillation: a primer for the primary physician. J Am Board Fam Med 2015;28: 510-22.

12. Post RE, Mendiratta M, Haggerty T, et al. Patient understanding of body mass index (BMI) in primary care practices: a two-state practice-based research (PBR) collaboration. J Am Board Fam Med 2015;28: 475-80.

13. Davis MA, Yakusheva O, Gottlieb DJ, Bynum JPW. Regional supply of chiropractic care and visits to primary care physicians for back and neck pain. J Am Board Fam Med 2015;28:481-90.

14. Sanyer O. Birthing and family medicine: more than obstetrics. J Am Board Fam Med 2015;28:535-6.

15. Puffer JC. A significant number of charter diplomates participate in American Board of Family Medicine (ABFM) maintenance of certification. J Am Board Fam Med 2015;28:439-40. 